\title{
Museums as a milieu of development of creative abilities of children
}

\author{
Olga V. Ivanova ${ }^{1, *}$ \\ ${ }^{1}$ ISED RAE, Laboratory of General Issues of Didactics, 105062, Moscow, Russia
}

\begin{abstract}
This article reveals the importance of creativity, features of development of a creative personality by the means of Museum pedagogy.
\end{abstract}

The development of creative personality, creative thinking is a complex process, demanding constant comprehension and attention to it. It is difficult to overestimate the importance of the formation of the creative personality because of the fact that it is concerned with the esthetic and moral education and the artistic taste formation. The losses in the esthetic upbringing impoverish the person's inner world. The person, who does not know the genuine values, accepts the false, imaginary values. Art, music, museums as well as possible help to develop the creative beginning in a person, they contribute to the creative activity implementation.

There are many determinations of the «creative work» notion, one of them looks like: «Creative work is an activity that produces new values, the ideas of the person as the creator» [1]. This activity allows to feel oneself as the creator of something special, to realize one's own ideas, it raises and makes him unique. Everyone feels special, exciting emotions when he manages to discover, devise, invent, construct, create something that does not exist yet or to improve something that has been created before.

Children are not burdened with the patterns of ready solutions yet, everyday and other problems, they are sincerely delighted with the beauty of the item they like, they draw what they want, they are able to be sincerely surprised. It is used to consider that every child is creative, talented and possesses the very rich imagination. In any case it is obvious that children have some natural potentialities and have ingenuousness which allows them to perceive the surrounding world vividly. Exactly these features are peculiar to the creative personality.

The creative person is endowed with special abilities: imagination, fantasy, ability to create new thought images. Sometimes these images are far from reality and in this case it is impossible to use them in the real life, therefore, it is very important to develop erudition, critic way of mind, observation, wish of self-improvement, will-power, persistency, capacity for work and activity in upholding their own opinion. The creative person is able to perceive the value, specificity and beauty in the object of art.

Many researchers consider that the creativity indicates the development of creative abilities.

«Creativity, or the person's creative abilities, is the ability to spawn unusual ideas, to sway from traditional ways of thinking, to solve difficult situations quickly» [2]

It is characterized by the increased intellectual activity for the employment of all the abilities of consciousness and unconsciousness with an aim oa finding more effective and original way of solution of the task.

In our opinion, it would be to use the term «sharpness of wit», which means the ability to find the nontraditional, brave and wittily solutions of any problem, using unspecialized means and resources, right along with the term «creativity».

It is very important to begin to introduce the children to the creative activities as early as possible, while they are still interested in everything. To achieve this target the mini-museums, art studios, vocal study groups are being created in educational establishments, some classes take place in museums.

Such classes are one of the most effective ways of children's art abilities development. Nowadays people understand the importance of the development of the museum pedagogy. In fact, in every museum in Russia the department of museum pedagogy works very actively. It develops and realizes special educational programs, conducts courses of classes for the children of preschool and school ages.

Unfortunately, this work is supported mostly by enthusiasts, because it is not compulsory, but additional. The visit of children to the classes in museums depends on the will of administrators of educational establishments and teachers. The pedagoguepractitioners, who use the elements of museum pedagogy in their work, note that systematical classes in museums stimulate some special interest for the study, acquiring new knowledge, develop imagination and creativity of the students. As they believe, the most interesting lessons in museums are History, Geography, Biology, 
Art, Literature, World Art Culture. All seen and heard at the museum, also the understanding of the environment the children comprehend deeper, their attitude to it is expressed in their logical thinking, drawing, telling the stories, composing. Thus, the museum is the special activity milieu, that can support the development of children's creativity.

At the meeting of Vladimir V. Putin and Russian museums directors on April 5, 2012 the ex-minister of Culture A.A. Avdeev suggested an interesting and, in our opinion, right idea: «The curriculum should be connected with museums activity. We visit museums occasionally, so, we need to include the visiting museums in the curriculum» [3].

The first museum curriculums «Museum and culture» (by E. G. Vansalova), «The material world of culture» (M. U. Yuchnevich), «Greetings, museum!» (by the scientific adviser B.A. Stolyarov) were worked out in the 1990-ies in Moscow and St. Petersburg. Later, the similar curriculums started to get worked out in other regions.

According to the fair note of E.B. Medvedeva: «For the following years, the number of the published museum curriculums practically has not increased. Only the rate of mentioning the term «museum curriculum» at the museums has become higher. It has become only the set of excursions, museum lessons, lectures that museums suggest for the students of a certain age» [4]. Almost all museum curriculums have been published in small editions, and mainly tested in the format of the experiment.

The museum curriculum of the Russian museum called «Greetings, museum!» (by the scientific adviser B.A. Stolyarov) is the most common one. It corresponds to all modern standards of the interaction of museums and educational establishments. It was approved by the Ministry of Education of the Russian Federation. In this curriculum the educational goals, the choice of teaching methods and the choice of gradually introducing the children to the Museum based on their educational interests and age characteristics are defined clearly, the use of museum material in the classroom at school is provided, there are also scenarios of museum lessons. In 2003 this educational program was awarded by the State Prize of the Russian Federation in the sphere of literature and art.

With the help of the proper organized museum lessons some educational problems, concerning the formation of the definite features peculiar to the creative personalities can be solved. The main tasks in this case are:

- Introduction of the children to the world of art and development of artistic culture in conditions of a sociocultural milieu of the museum;

-Development of culture of perception of the language of art, the formation of creative thinking;

- Introduction of cultural values in the sphere of vital interests of the child;

- Education of careful attitude to cultural heritage.

During the planning of museum lessons some important pedagogical conditions cannot be neglected, without them a creative personality cannot be formed. Let us refer to the most principal of them:

- Planning museum lessons, it is necessary to consider both psychological and age peculiarities of the group: the level of maturity, the degree of organizational, psychological, intellectual and emotional unity. The knowledge of psychological peculiarities of children allows to choose the corresponding forms of practice, to determine the content to organize and have classes. For example, in elementary school children the mechanical memory is more developed, they are characterized by fatigue and loss of interest due to a lack of physical activity. Therefore, during the museum lessons the younger children must have physical exercises. The children are very fond of role playing, so, why not arrange a staging with the costumes? Why not offer them to dream up? Dialogues, dances, songs, physical flexing, outdoor games, stories, movement to music, singing, and timely promotion of successful activities will help to develop interest to the creative activity;

-Organizing a group work. "The most productive educational activity in the situations of communication, that contributes to the creation of the special communication environment, the open ideas exchange, effective solutions of the problems, the realization of creative ideas is the group work $<\ldots>$ ।» [5].

To develop the children's creative abilities it is very important to use musical instruments, easels for drawing, plasticine, clay etc. at the museum lessons. This is to ensure that during the lesson the children could try themselves in the role of artist, painter, sculptor. The decoration of the museum halls, especially created directly in an educational institution, is extremely vital and important. For example, painted wooden ware, wicker panels and baskets, cloth dolls, and embroidered pictures, pottery and figurines, etc. create a unique supportive atmosphere. In such an atmosphere the master-classes of folk arts and crafts are often conducted. In the museum of country life, looking at masters wearing the stylized costumes, children show great interest in their work and are happy to express their wish to learn the basics of crafts. Of course, the museum's program couldn't avoid the fiction. Some of the museums organize the themed literary soirees, where one can witness the times of one or another writer or the poet, to try to tell a story, or a poem, to discuss the most favorite work or character.

Which forms of cultural and educational activities are the best to develop creative abilities of the children? Certainly, it mostly depends on the age and interests of the children. There is no doubt they should be varied and original. The contests, competitions, trivia are the effective ways to increase the creative activity of the children, to develop their creative abilities and skills.

Such form of work as meetings with the famous creative workers gives the children the opportunity to speak with famous children's writer, musician, poet, scientist and to ask them questions. The children will remember their impressions after those meetings, for a long time and besides, it is a great incentive to start the creative activities! 
The concerts, literary evenings also give an excellent result, especially if the children take part themselves and their parents present as the audience. In this case, the children are already at the stage of preparation for a concert engaged in creative work! They learn to play different roles (this is a great development of creative abilities, realization of creative energy) they develop their imagination and talent for improvisation.

The holding of the event in the museum is a good opportunity to introduce children to art and culture. The theme of the holiday may be limited only by the capabilities of the museum: "Day of the Chemist", "Day of Radio", a significant historical dates, birthdays of famous artists, "Day of Museums ". The celebration of "Day of Museums" has become a good tradition in Russia. Of particular interest is the fact that in this day museums work even at night. Usually on this day a variety of interesting creative programs are preparing in museums. What is interesting in these forms of creative work for children? Children are attracted to personal involvement, the participation in an event, thanks to the drama, the game, in direct communication with the characters of the festive events, unusual attributes and the opportunity to show their creativity.

The rapid development and implementation of information technology affects the educational system. Museums and educational institutions successfully use interactive boards, educational tablets, e-application with visual material and tasks, create portals, websites. These technical innovations allow us to make the learning process open to the public and interesting and effective for children.

The placement of the educational content on the official website of the educational organizations or museums or the creation of a special educational portal is a promising innovative form of distant educational work with children, which can develop their creativity. The uniqueness and success of this work lies in the fact that it is possible to focus on the collective, independent, individual work with children.

However, after analyzing the content of modern official websites of museums and educational organizations it can be concluded that they focus on the adult. 30 sites of Russian museums chosen randomly have been analyzed (some of them are among the top 100 best Russian museums, some of them are not so famous).

The purpose of their establishment and functioning is to fulfill the requirements of Russian legislation - placing official information about their activities; selfpresentation; engaging visitors, not the creation of a unified educational information environment that is child centered.

Despite the fact that $70 \%$ of museum websites have the tab "children", in $90 \%$ of cases, it again focused on adult and contains promotional information on activities for children, reports on their implementation, and only $10 \%$ of sites have information that can be interesting for a child (educational online games, children's stories describing the museum). Unfortunately, even these $10 \%$ of the sites cannot be attributed to educational resources (Table 1).
The modern Russian museums conduct a great cultural and educational work with children of all ages: preschoolers, schoolchildren, students. The educational programs are developed, the classes are conducted and the training tasks for self-dependent work are given. Many museums will adapt their educational programs under the school curriculum that allows to integrate the museum classes into the school educational process. These programs can be used both in the classroom and in the museum groups for children of the same age from different schools. There are educational programs of museums that focus solely on the child's age, capabilities and specifics of the museum. Undoubtedly, this allows to develop creative abilities and creativity.

Table 1. Cultural and educational content of museums' websites.

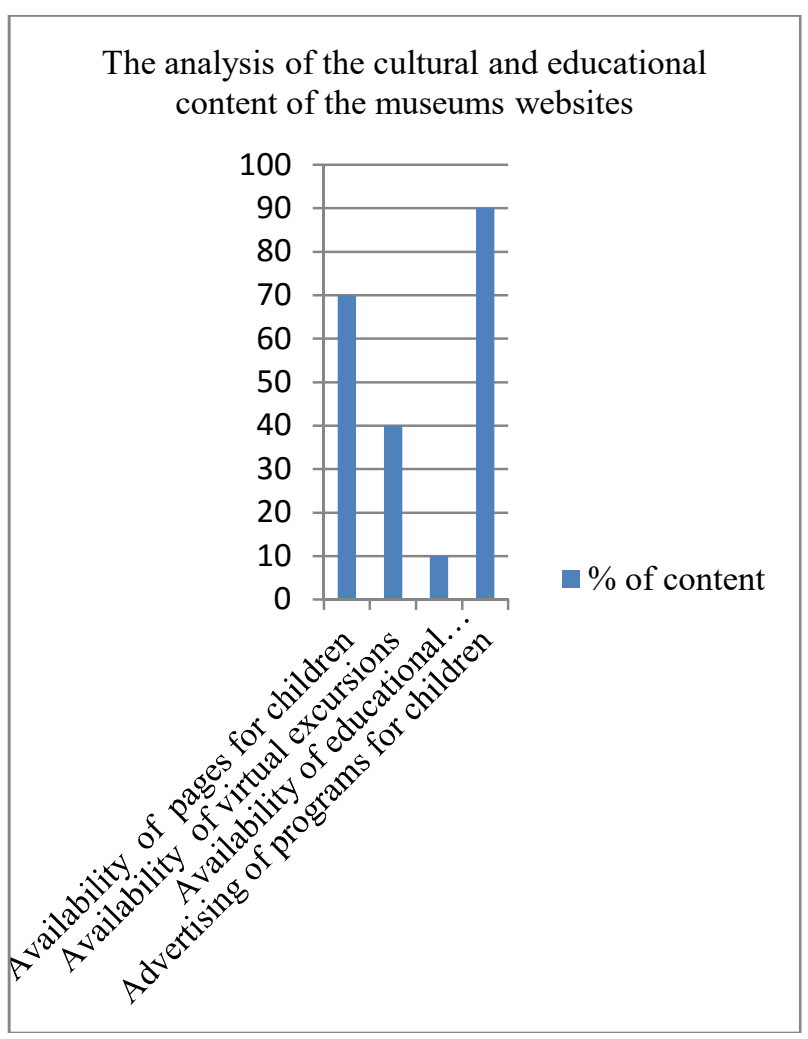

Despite the inconsistency of the content on today's websites and analyzing the experience of museums, there is confidence that the majority of the assignments, tests, educational material used during the on-site museum lessons can be adapted for placement on the website. This will improve the level of perception of the information by a child and will become a great addition to the museum and school lessons.

The creation of a unified information space can become a powerful educational resource, subject to the fulfillment of its educational and cultural content, creative tasks, tests, educational games, and educational materials. This will allow museums and educational organizations to remotely conduct joint cultural and educational activities, to arouse interest in the culture, to the museum, to develop creativity, to diagnose the 
results of the cultural and educational work, to cooperate more effectively.

The unified information space will allow to carry out serious preparatory work preceding full-time museum employment. The child will be able to find an available for his age information about the exhibition and theme of classes, to pass cognitive-game test, get a creative task, which he can execute coming to the museum. Thus, children will be interested in culture and creativity and museum studies. The museum will become not an antique things storage, but a source of knowledge. For museum educator this work is no less important. Interacting with children through the Internet, he will be able to assess the level of training of the child and adjust the lesson face-to-face so that it was with one hand interesting and attractive for the child, and accurately completed the task. The museum and educational organization of such a space will allow for a diagnosis of learning material, questionnaire survey of children before and after class in the museum.

The virtual museum is a new effective form of work with visitors of the museum. It is not specifically adapted to work with children, however, may be used. The child likes to use the opportunity to visit the virtual museum after class in the museum, in order to consolidate the result. The teacher can use this resource in their work to visit the museum without leaving the classroom. This possibility wipes out the temporal and geographic limitations. Unfortunately, only $40 \%$ of museum websites (well-known Russian museums) make it possible the remote access to the museum.

The experience of interaction between educational institutions and museums can be quite productive. However, the results can be much better if the classes will be conducted systematically and integrated, and the decision on conduction of classes in a museum, or a decision on the organization of the school, preschool museum will depend not only on the willingness of the teacher or the head of an educational organization.

\section{References}

1. Dictionary of the practical psychologist. Available online: URL http://psychology.academic.ru/1001 (accessed 08.04.2016)

2. Philosophy: Encyclopedic dictionary (Gardarikiб Moscow, 2004). Available online: URL http://dic.academic.ru/dic.nsf/enc philosophy/1200 (accessed 08.04.2016)

3. RIA Novosti. Available online: URL http://ria.ru/edu news/20120405/619094963.html (accessed 08.04.2016)

4. E.B. Medvedeva, Actual problems of the modern museum, 8, 48 (2010)

5. S. V. Ivanova, Values and meanings, 2, 102 (2010) 